\title{
A formação dos tempos compostos em português nos séculos XVII e XVIII
}

\section{The formation of Portuguese compound tenses in the $17^{\text {th }}$ and $18^{\text {th }}$ centuries}

\author{
Juan M. Carrasco González \\ Universidad de Extremadura \\ jcarrasc@unex.es
}

\begin{abstract}
Resumo
O propósito deste trabalho é analisar a evolução dos tempos compostos em português (com os auxiliares TER, HAVER e SER), entre os séculos XVII e XVIII, como continuação de estudos prévios sobre o século XVI e primeira metade do século XVII. Para isso, será analisado um corpus constituído pela obra do Pe. António Vieira em comparaçáo com vários textos do século XVIII. Para a formaçáo dos tempos compostos no período clássico, foram considerados os contributos de Carrasco, Mattos e Silva e, muito especialmente, Harre, o único até ao momento dedicado a este período. $\mathrm{O}$ facto de não utilizar grandes corpora linguísticos permite uma análise mais pormenorizada de cada caso, bem como estabelecer conclusôes a propósito de diferentes registos de língua e usos estilísticos. Por outro lado, o corpus utilizado é, especialmente no caso do padre António Vieira, muito extenso e suficientemente significativo, não só para documentar cada construçáo de tempo composto, mas também para avaliar a sua evoluçấo no período selecionado.
\end{abstract}

\section{Palavras-chave}

Evolução dos tempos compostos; verbo ter; verbo haver; verbo ser

\section{Sumário}

1. Introdução. 2. Corpus. 3. A formação dos tempos compostos na obra do Pe. António Vieira com ter. 4. A formação dos tempos compostos do Pe. António Vieira com HaVer. 5. A formaçóa dos tempos compostos na obra do Pe. António Vieira com SER. 6. Os tempos compostos no século xviII. 7. Outros indícios de gramaticalização. 8. Conclusôes.
Recibido o 23/04/2019

Aceptado o 01/02/2020

\begin{abstract}
The aim of this article is to analyse the evolution of Portuguese compound tenses using the auxiliary verbs TER, HAVER and SER, between the 17 th and 18 th centuries, following previous studies on the 16th and the first half of the 17 th centuries. This analysis is based on a corpus of works by Fr António Vieira which is compared to 18 th century texts. For the formation of compound tenses in the classical period, the contributions by Carrasco, Mattos e Silva and, most especially, Harre -the only scholar until now to study this period- were taken into account. By not making use of large linguistics corpora, it is possible to obtain a more detailed analysis for each case, and to reach conclusions on different language registers and stylistic usages. On the other hand, the corpus analysed, particularly that of Father Antonio Vieira's, is very comprehensive and sufficiently significant, as to not only document each Portuguese compound tense construction, but also to assess its evolution in the period under study.
\end{abstract}

\section{Key words}

Evolution of the compound tenses; verb 'ter'; verb 'haver'; verb 'ser'

\section{Contents}

1. Introduction. 2. Corpus. 3. The formation of compound tenses in the work of Father António Vieira with TER. 4. The formation of compound tenses in the work of Father António Vieira with HAVER. 5. The formation of compound tenses in the work of Father António Vieira with SER. 6. The compound tenses in the $18^{\text {th }}$ century. 7 . Other signs of grammaticalisation. 8. Conclusions. 


\section{Introdução}

Catherine E. Harre (1991: 129-153) fez uma revisão da história completa dos tempos compostos em português desde a Idade Média até aos nossos dias, inclusivamente em comparação com o espanhol e outras línguas românicas, mas tem sido pouco utilizada e citada pelos especialistas em diacronia de Portugal ou Brasil, talvez por causa do título, alusivo ao verbo castelhano tener: Tener + Past Participle. A case study in linguistic description ${ }^{1}$. Os resultados deste trabalho precursor para o período que nos interessa ${ }^{2}$ não estarão errados em grandes traços, mas não conseguiram apurar os pormenores caraterísticos do período clássico (séculos XVI, XVII e XVIII) por causa da amplidáo do seu estudo ${ }^{3}$. Na data em que publicou o seu trabalho, o conhecimento sobre o uso de TER + PP na história da língua portuguesa era muito maior do que em espanhol, "probably because, in contrast with developments in Spanish, ter + past participle was eventually victorious over haver + past participle, and is now the usual perfect auxiliary construction" (Harre 1991: 129). É interessante notar, a respeito desta opinião, que nos estudos de diacronia sobre o português isso mesmo aconteceu no caso de HAVER + PP, cujo conhecimento era muito inferior ao uso de HABER + PP em espanhol porque neste idioma acabou por ser a única construção possível para os tempos compostos, se bem que ainda sobrevivam construçóes de TENER + PP em variedades regionais ou em usos não gramaticalizados.

Da professora Mattos e Silva apenas cita um artigo (Mattos e Silva 1981), ignorando as suas monografias sobre a morfossintaxe do português antigo, algumas posteriores ao estudo de Harre, (Mattos e Silva 1989 e 1993, esta última incluída em 2006) e, muito especialmente, os trabalhos sobre o português clássico que mais interessam a este artigo (Mattos e Silva 2002a e 2002b). As conclusóes de Mattos e Silva, que não refere o estudo de Harre, foram verdadeiramente surpreendentes: o verbo haver deixou de ser usado para a formaçáo dos tempos compostos na primeira metade do século Xvi, pelo menos na linguagem da corte representada pela obra de João de Barros e pela documentação produzida pelos escrivães de D. João III - o que, de facto, constitui um corpus relativamente reduzido ${ }^{4}$. Porém, a literatura barroca do

1. Náo é o caso, por exemplo, de Martim Becker (2016), que nesta mesma revista refere o trabalho de Harre no seu estudo sobre o pretérito perfeito composto.

2. Uma sintética análise contrastiva da origem dos tempos compostos em português e em espanhol, até ao fim da Idade Média, pode ver-se em Carrasco (2015: 80-82).

3. É considerada a definição do período clássico da língua portuguesa e as suas balizas cronológias como foram propostas por Mattos e Silva (citada em seguida), Castro (2006: 185-200) ou Cardeira (2012, 2013), entre outros.

4. Os resultados do estudo de Osório (2008), por outro lado excecional, parecem não coincidir com Mattos e Silva e Carrasco para o século Xvı, mas isso é devido às caraterísticas do corpus utilizado: o Corpus Informatizado do Português Medieval da Universidade Nova de Lisboa (http://cipm.fcsh.unl. pt) só disponibiliza textos dos primeiros anos de Quinhentos (ver Carrasco 2019). 
século XVII, analisada na obra de D. Francisco Manuel de Melo (ver Carrasco 2015), mostrou uma recuperação extraordinária no uso de HAVER + PP, sendo em muitos casos maioritária, muito embora as estatísticas sejam caraterizadas pela variância, sem dúvida por causa do propósito estilístico com que se usa e, ao que parece, talvez por influência culta e literária dos autores barrocos espanhóis: de $28.1 \%$ de ocorrências de HAVER + PP em $A$ Visita das Fontes até $85 \%$ em Os Relógios Falantes. A escolha dos auxiliares TER ou HAVER ao longo deste período oferece os seguintes resultados: em meados do século XVI chegou-se a $0 \%$ de ocorrências de HAVER + PP (nos textos analisados por Mattos e Silva), no fim do século XVI e início do século XVII há uma recuperação leve do uso de HAVER (0\% em Duarte Nunes de Leão e 5.3\% em Rodrigues Lobo segundo a análise de Carrasco $2014^{5}$ ) que continua com mais vigor nas obras de Melo (36.8\% de HAVER + PP).

Para o estudo dos tempos compostos nos séculos XVI, XVII e XVIII, Harre apenas analisa três obras: a Verdadeira informação das terras do Preste João das Índias (1540) de Francisco Álvares, segundo a edição feita em 1943 por Augusto Reis Machado; as Cartas do Pe. António Vieira assinadas entre 1626 e 1647 segundo a edição que leva a cabo J. Lúcio d'Azevedo em 1925; e o Verdadeiro método de estudar (1746) de Luís António Verney em edição de António Salgado Júnior de 1949. Estas são as principais conclusôes do seu estudo:

1) Os primeiros exemplos convincentes de TER + PP com verbos intransitivos e reflexivos só aparecem no século xviı, na obra de Vieira (Harre 1991: 132).

2) A concordância de particípio e objeto direto com o auxiliar TER ainda acontece em $100 \%$ dos casos no século XVII e só no século XVIII, na obra de Verney, é maioritário o uso não concordante (25 casos de 34). Porém, no caso de Vieira, só três exemplos são formas indubitáveis de tempo composto gramaticalizado (Harre 1991: 132-133).

3) Os tempos compostos de HAVER + PP são menos que TER + PP no século XVI (13 e 6 casos) e no século XVII (61 e 12), tendo desaparecido completamente no século XVIII (Harre 1991: 136-138).

4) Já se verifica nas Cartas de Vieira que não existe concordância de objeto direto nos tempos compostos com HAVER (Harre 1991: 138).

5) O uso de SER + PP para os tempos compostos de verbos intransitivos e reflexivos era de $100 \%$ no século XVI, mas no século XVII é já minoritário (5 ocorrências de 26 casos) e desaparece no século XviII (Harre 1991: 140).

5. Também em Carrasco (2014) foi analisado o caso excecional de Sebastião Salgado, com $77.1 \%$ de ocorrências de HAVER + PP que é explicado como possível influência do castelhano, dado que o autor viveu em Espanha e escreveu obras também nesta língua. 
O propósito do nosso estudo é analisar os tempos compostos em português desde a segunda metade do século XVII até ao fim do século XVIII, na sequência de trabalhos anteriores sobre o século XVI e primeira metade do século XVII já citados, ampliando quantitativamente o corpus linguístico em relação ao estudo de Harre. As obras escolhidas respondem ao português culto da época, representativas do padrão da corte lisboeta, sem regionalismos ou variantes dialetais, mas de géneros diferentes, de modo que se possam verificar diferentes usos estilísticos, como acontecia na obra de D. Francisco Manuel de Melo. Quis incluir também dentro do corpus duas peças de teatro do fim do século xviII para uma primeira aproximaçáo, nem que seja muito incompleta, a outro registo ou modalidade de língua mais coloquial ${ }^{6}$.

Os elementos de análise são os mesmos que Harre, Mattos e Silva e Carrasco propuseram para seguir a evolução da construção dos tempos compostos neste período: a) A escolha de TER, HAVER e SER como verbos auxiliares; b) A gramaticalização dos tempos compostos com TER e HAVER ${ }^{7}$, entendendo que haverá mais gramaticalização se os verbos auxiliares nos tempos compostos deixam de realizar as mesmas funçóes paradigmáticas que têm quando não fazem parte de uma construção de tempo composto e, nesse processo histórico de gramaticalização ${ }^{8}$ deverá verificar-se se: b.1) o PP não faz concordância com o objeto direto quando TER e HAVER aparecem com verbos transitivos; b.2) ambos auxiliares podem formar tempos compostos com qualquer verbo9; b.3) não é possível a anteposição do pp ao verbo auxiliar; e b.4) não existe interpolação ou é progressivamente menos importante porque aparecem menos elementos interpolados ou menos ocorrências de interpolação ${ }^{10}$.

6. Nos últimos tempos estấo a realizar-se interessantes projetos de diacronia que nos aproximam muito melhor a registos coloquiais da língua com recurso a outro tipo de textos, como as cartas privadas. É o caso do projeto liderado por Rita Marquilhas no Centro de Linguística da Universidade de Lisboa Post Scriptum: Arquivo digital da escrita quotidiana em Portugal e Espanha na Época Moderna. http://ps.clul.ul.pt/ [23/09/2019].

7. Não houve o mesmo processo de gramaticalização nos verbos compostos com SER, mas um paulatino abandono do seu uso.

8. "A gramaticalização é considerada paradigma se observada num estudo da língua que se preocupe em focalizar a maneira como formas gramaticais e construçôes surgem e como são usadas. É considerada processo se se detiver na identificação e análise de itens que se tornam mais gramaticais" (Gonçalves / Lima-Hernandes / Casseb-Galvão \& Carvalho 2007: 16). A gramaticalização em diacronia entende-se como o processo pelo qual um elemento da língua transforma-se em mais gramatical, e é descrito assim, sem grandes diferenças, desde os primeiros autores que desenvolveram pesquisas sobre gramaticalização, como Givón (1975), Hopper (1991) ou Lehmann (1985).

9. A gramaticalização faz com que os auxiliares TER e HAVER percam a sua transitividade, de tal modo que podem formar tempos compostos com qualquer tipo de verbo.

10. Note-se que os fenómenos b.3) e b.4) fazem parte do processo de gramaticalização porque é mais gramatical um tempo composto quando as duas partes de que é constituído (verbo auxiliar e verbo principal) formam uma unidade, de tal modo que náo seja possível alterar a ordem dos seus elementos nem interpolar outras formas entre eles. Repare-se que, no português moderno, a interpolaçáo é pos- 


\section{Corpus}

O corpus foi constituído, em primeiro lugar, pela obra do Pe. António Vieira como exemplo de língua culta da segunda metade do século XVII ${ }^{11}$. Foram escolhidas obras pertencentes a géneros diferentes (epistolar, sermonário e ensaístico) com o intuito de abranger uma maior riqueza expressiva:

- Cartas (Vieira 1854). A edição princeps apareceu em dois volumes em 1735. Foi analisado o Tomo I da edição de 1854, que náo coincide com o primeiro volume da princeps. A primeira carta tem a data de 30 de setembro de 1647 e a última carta é de 25 de janeiro de 1674 , ocupando a parte central da segunda metade do século XVII.

- Sermóes (Vieira 2008). É a reprodução dos dois primeiros volumes dos sermôes publicados pelo autor, em 1679 e 1682 . Foram pregados desde 1644 (o Sermão da Glória de Maria, Mãe de Deus) até 1672 (o Sermáo da Quarta-Feira de Cinza). Ainda que publicado em 1679, a dedicatória do primeiro volume, Ao Principe Nosso Senhor, foi assinada em 1677. Os últimos volumes por ele próprio preparados apareceram depois de ter morrido, em 1697. Os Sermóes são boa mostra da língua de toda a segunda metade do século XVII. A edição utilizada não numera as páginas, de modo que as citaçóes são referidas pelo nome dos sermóes e o parágrafo ou parte numerada com que o Pe. António Vieira os dividia. Além disso, contém vários erros que corrigimos. Assim, o terceiro dos sermóes reproduzidos aparece sem título - trata-se do Sermáo do Santíssimo Sacramento, pregado em Santa Engrácia de Lisboa em 1645. Quanto ao segundo volume, só foram reproduzidos os primeiros quatro sermóes dos quinze que se imprimiram na princeps. Esta edição foi cotejada com os exemplares originais disponibilizados pela Biblioteca Nacional de Portugal (Vieira 1679 e Vieira 1682).

sível, mas muito mais restrita do que no português clássico. Estes mesmos elementos foram analisados no processo de gramaticalização dos tempos compostos noutras línguas românicas, como é o caso do castelhano (ver Carrasco 2015: 80-81).

11. Ninguém discute o caráter modélico que Vieira tem para a prosa culta do século Xvir: "A obra de Vieira ficou durante muito tempo como um dos paradigmas da prosa portuguesa, e ainda hoje é um dos seus bons modelos" (Saraiva \& Lopes 1982: 557). Mas também é verdade que podia servir igualmente qualquer obra culta da época desde que se sujeitasse às condiçóes expostas. O mesmo podemos dizer para as obras do século XviII: outras muitas podiam ser escolhidas (em certa medida, todas), mas estas servem sem dúvida ao nosso propósito. São obras, aliás, que interessam pela cronologia, não só da edição impressa ou manuscrita, mas também do período de vida dos autores, para que representassem diferentes momentos dos séculos XVII e XVIII. Algumas caraterísticas que refiro na sua descrição também foram decisivas para a escolha destas obras. 
- História do Futuro (Vieira 1718). A obra foi escrita em 1665-67 (mas só publicada em 1718) como defesa contra o processo inquisitorial em que seria condenado por opiniōes heréticas expostas no seu livro Esperanças de Portugal, quinto império do mundo... O facto de ser condenado primeiro e amnistiado mais tarde, fazia inútil a continuação da obra, de tal modo que ficou incompleta.

Para o século XVIII foi analisada, em primeiro lugar, a Vida e açóes do famoso e felicíssimo Sevagy da India Oriental (Pacheco 1730). O livro imprimiu-se atribuído a Cosme da Guarda, nome figurado que o Dicionário Bibliográfico de Inocêncio Francisco da Silva (1987: 8-9) identifica com Caetano de Gouvêa Pacheco, clérigo teatino nascido em 1696 e morto em Lisboa em 1768. O autor narra a vida de Sevagy como se tivesse sido testemunha da sua vida. Inclusivamente oferece datas fictícias do momento da escrita: "Tanto que Cubatghan recebeu a carta, a levou ao Rey Oranzeb Grão Mogol, que havia annos que reynava, e reyna ainda hoje 28. de Agosto de 1695" (Pacheco 1730: 40). Sabendo quando nasceu o autor, é claro que nada disto pode ser verdade: trata-se de uma obra escrita no primeiro terço do século XVIII, de língua culta como correspondia às obras historiográficas da época.

O Elogio do Condestável D. Nuno Álvares Pereira (Oliveira 1798) representa a língua culta da segunda metade do século xvirI. $\mathrm{O}$ autor foi professor de retórica e poética em Lisboa "pela resoluçáo regia de 10 de Novembro de 1771, com exercicio no Collegio Real de Nobres, e depois no antigo estabelecimento d'estudos do bairro d'Alfama, [...] morrendo (ao que parece) no [ano] de 1823, ou pouco depois" (Silva 1996: 93). Essa mesma edição inclui, desde a página 147, o Elogio de Afonso de Albuquerque, que também foi analisado.

Para uma aproximação à oralidade, foram escolhidas duas comédias:

- O criado de si mesmo (Anónimo 1788), manuscrito, cópia autógrafa de António José de Oliveira. Segundo a catalogação da Biblioteca Nacional de Portugal, é "provável cópia de El amo criado", isto é, Donde hay agravios no hay celos, y amo criado de Francisco de Rojas Zorrilla (1607-1648). Foi impressa em 1782 e em 1789 sob o título de Dom Joáo de Alvarado, o criado de si mesmo: Comédia Nova. Aparecem personagens de diferentes classes sociais sem traços regionais ou dialetais.

- Os peraltas mascarados em Almada (Anónimo 1790), impresso. Muito mais próximo da oralidade. Nenhuma personagem pertence às classes altas. Não há traços dialetais ou regionais.

Para a análise do corpus foi utilizado o software AntConc realizado por Laurence Anthony na Universidade de Waseda ${ }^{12}$.

12. AntConc 3.5.7 [Software]. Tokyo, Japan: Waseda University. Disponível em http://www.lau- 


\section{A formaçáo dos tempos compostos na obra do Pe. António Vieira com TER}

Os verbos auxiliares não podem formar um predicado completo porque precisam de ser associados a um verbo principal, de tal modo que, segundo Maria Helena de Moura Neves, os verbos auxiliares na formação de tempos compostos são meros "operadores gramaticais" porque não constituem predicados (Neves 2000: 61-65). São, portanto, verbos semanticamente vazios no mesmo sentido, embora com função diferente, do que os verbes supports propostos por Gross (1981) ${ }^{13}$. Para além de receber os morfemas de pessoa e tempo, o verbo auxiliar apenas exprime a noção de passado: "Os verbos ter e haver, construídos com particípio, formam tempos compostos de passado" (Neves 2000: 64). Ora, na língua clássica isto nem sempre era assim. No caso do auxiliar TER, há ocasióes em que não aparece esvaziado semanticamente, de tal modo que, por princípio, serão considerados verbos auxiliares na formação de tempos compostos neste período quando exprimam a noção de passado, quando possuam um conteúdo temporal de pretérito, independentemente de estarem ou náo esvaziados semanticamente. O conteúdo semântico de TER com objeto direto está relacionado com a noçáo de posse ou fazendo parte do que Mattos e Silva (1995) denominava "estruturas de posse", que, relativamente ao objeto possuído, apresentam três tipos pertinentes para a diacronia: a) bens adquiríveis materiais, b) bens ou qualidades adquiríveis imateriais e c) qualidade inerente, não transferível, do possuidor ${ }^{14}$.

Não serão considerados, portanto, os casos em que TER + PP não exprima uma noção de tempo passado. $\mathrm{Na}$ História do Futuro, encontramos estas cinco ocorrências indubitáveis sem conteúdo de pretérito: por isto [a primeyra figura] tinha a testa dividida em dous cornos (74); porque costuma Deos ter algumas cousas encubertas, \& escondidas por muytos seculos (189); que [Deos Soberano] nos não deyxa comprehender, nem alcançar os segredos de seus intentos [...], para nos ter sempre suspensos na expectação, \& pendentes de sua providencia (198); a cegueyra Judaica, porque tem os olhos cubertos com aquelle antigo vèo de Moysés (203); Estes taes haviaó de ter a testa virada para as costas, como dizem os Italianos dos Alemães, que todos se occupaó na erudição do passado (215).

renceanthony.net/software [18/03/2019].

13. De facto, o próprio Gross alude a esta relaçáo entre alguns verbos suporte e os verbos auxiliares: "Dans un premier temps, nous pouvons également considérer les extensions de verbes supports comme des auxiliaires s'insérant devant des verbes" (Gross 1981: 33).

14. Mattos e Silva utiliza a estrutura de posse segundo a definição de Pottier, para o qual existem estruturas de posse sempre que haja uma relação de dependência entre o predicado e o sujeito: "La voix pos met en relation deux éléments en établissant des liens de dépendance" (Pottier 1978: 29). O uso de TER e HAVER com as três estruturas de posse é uma das balizas que Mattos e Silva propóe na passagem do português médio para o português clássico ou moderno. Segundo Brocardo (2014: 132-137), nestas estruturas de posse, TER e HAVER não eram usados indistintamente em fases antigas da língua. De facto, TER só adquire um sentido muito geral em época posterior a HAVER, talvez no português médio, o que faz com que só então possua um funcionamento como verbo leve e que, por outro lado, "venha também a gramaticalizar como auxiliar" (Brocardo 2014: 136-137). 
Os casos de concordância com o verbo TER são já muito escassos relativamente a todas as ocorrências possíveis, isto é, todos os casos de TER com verbo [+ transitivo] e objeto direto feminino ou plural ${ }^{15}$. Se não consideramos os cinco exemplos citados em que não existe expressão de pretérito, há 35 casos nesta situação, e só 5 deles com concordância (v.gr., do vèo da infidelidade com que os Judeos tem cubertos os olhos para naô ver a Christo, 243), de modo que o uso habitual é o de não fazer concordância: depois de um Anjo lhe ter declarado grandes mysterios (194), sua Omnipotencia tinha fundado a terra sobre a agua (267), a mesma obra, que tinha começado (324), quasi todos os que atègora tenho allegado (330), etc. No total, há 100 casos de tempos compostos de TER com verbo [+ transitivo], dois deles em que dois particípios compartilham um mesmo auxiliar: o pouco que por mercè do Ceo temos alcançado, \& conhecido (37). Foram incluídos aqui casos de objeto direto com preposição 'a', uso caraterístico da língua clássica: com os muros de Milaó tinha sitiado a Portugal (94).

Com verbo [-transitivo] é bastante frequente o uso de TER como auxiliar: 31 ocorrências. Exemplos: que se tinhão escondido pelas brenhas (69), depois de terem cahido no primeyro erro (263), do mais illustre Profeta, que tão expressamente tinha fallado nesta gente (300), etc.

No caso dos Sermóes, encontramos também exemplos de TER + PP sem expressão de pretérito, mas os casos indubitáveis não são muitos e por vezes é necessária uma interpretação bem contextualizada. Por exemplo, no Sermão da Terceira Dominga da Quaresma, o $\mathrm{P}^{\mathrm{e}}$. António Vieira descreve a cena do filho pródigo com o pai argumentando que as coisas não deviam ter corrido como as apresenta; deste modo, o que temos diante é uma representação errada: Enfim temos a comédia turbada (\$I). Outro caso interessante confronta aparentemente, na descrição de um facto, o pretérito perfeito simples e o pretérito perfeito composto: o amor e liberalidade com que para vos encher de graças, abriu e tem aberto o lado (Sermão da bula da S. Cruzada: \$XI). Neste caso não parece que tem aberto transmita a noção de passado, porque não faz sentido afirmar que "não só abriu o lado, mas também tem aberto o lado". O que o Pe. António Vieira queria exprimir é que Jesus Cristo permitiu que uma lançada abrisse o seu costado no passado, estando na cruz, e que ainda hoje mantém essa ferida aberta para nos encher de graça ${ }^{16}$.

15. Dado que o verbo TER, nestes casos, não está esvaziado semanticamente (ainda exprime a noção de posse, segundo a proposta de Mattos e Silva), Paulo Osório não considera que se possa falar de verdadeiros tempos compostos: "A partir do momento em que [o Particípio Passado] deixa de sofrer flexão transforma-se em tempo composto” (2008: 5). Na minha proposta de análise, seguindo o processo de gramaticalização, estes casos apresentam uma forma menos gramaticalizada dos tempos compostos. 16. Não pretendo estudar aqui o uso dos diferentes tempos compostos na língua clássica. Pelo contrário, apenas preciso de verificar se o uso de TER + PP é ou não é tempo composto segundo os critérios anteriormente estabelecidos. Neste caso, não interessa o facto de tem aberto corresponder, na forma, com o moderno pretérito perfeito composto, porque nesta frase não exprime a noção de passado e, por conseguinte, não pode ser considerado um tempo composto. Isto náo quer dizer que 
Outros casos não admitem dúvida, como este de dois particípios ("tinham dividida e unida"): De maneira que a mesma semelhança que as criaturas tinham com Adão, dividida, e por partes, era semelhança; unida, e por junto, era diferença (Sermão de Santo Inácio: \$IV). Também estes casos: Comparado o martírio com o Batismo, não tem conhecida vantagem (Sermão da bula da S. Cruzada: \$VIII); como cabeça espiritual e temporal tinha dobrada obrigação de não consentir (Sermão da Terceira Dominga de Quaresma: \$II); Nenhuma nação do mundo tem mais facilitada a fé do Santíssimo Sacramento que os judeus (Sermão do Santíssimo Sacramento em Santa Engrácia: \$II); Que os homens sejam maiores inimigos que os demônios, é verdade que eu tenho muito averiguada (Sermão no Sábado Quarto da Quaresma: \$II). A estes devemos acrescentar 4 ocorrências da expressão "ter os olhos abertos", como: foi ser cegueira de homens que tinham os olhos abertos (Sermão da Quinta-Feira da Quaresma: \$II). Também ter os olhos postos e fixos em uma parte (idem: \$III) e tinham os olhos presos (idem: \$III). No total, são 14 ocorrências em que TER + PP não exprime tempo pretérito - contando como duas diferentes quando dois particípios compartilham uma forma de TER.

Há nos Sermóes 349 ocorrências de TER + PP que, sem contar os casos que não exprimem tempo pretérito, resultam em 335 casos de tempos compostos com TER, como nestes exemplos: Tendo o céu engrandecido tanto a Isabel, tendo-a sublimado a um lugar tão alto de perfeição (Sermão da Rainha Santa Isabel: \$III); Já tenho vencido o certame, já tenho acabado a carreira (Sermão de Quarta-Feira de Cinza em Roma: \$IV); já seus méritos a tinham canonizado e colocado no céu (Sermão da Rainha Santa Isabel: \$III); Faltou-lhe o sangue, porque tinha derramado ali e em tantas outras partes (Sermão da Bula da Santa Cruzada: \$IV); etc. Destes 335 casos, 16 apresentam concordância de pp e objeto direto: Se eu me não engano, tenho bem imaginada a prova desta verdade (Sermão do Santíssimo Sacramento em Santa Engrácia: \$VII); sendo os procedimentos de Davi tão retos, como ele reconhecia, jurava e tinha experimentados (Sermão da Terceira Quarta-Feira de Quaresma de 1670: \$VII); Como ele tinha já destinadas as pessoas, a quem havia de fazer o provimento (idem: $\$ \mathrm{VI}$ ); etc. Note-se que um caso de tinha rendida (Sermão da Primeira Dominga de Quaresma: \$V) é um erro da edição moderna - o que condiz com o facto de o objeto direto ser Cristo, masculino singular. Na lição

exemplos como este não estejam relacionados com a evolução do pretérito perfeito composto, extraordinariamente complexa no caso da língua portuguesa (relativamente a outras línguas românicas) e difícil de sistematizar diacronicamente porque o seu processo evolutivo "se desenrolou dentro de uma margem de variação impressionante" e com "a presença simultânea de leituras innovadoras e tradicionais” em autores dos períodos clássico e moderno (Becker 2016: 40). Note-se que o pretérito perfeito composto em português possui hoje em dia um forte valor aspectual iterativo, o que explica que algumas gramáticas modernas classifiquem o verbo TER com particípio passado nalguns casos fora da categoria dos verbos auxiliares de tempo. Por exemplo, Maria Helena de Moura Neves classifica TENHO SAÍDO com ele, ido a todos os lugares que quero conhecer ou TEM COMPRADO muitos diamantes? dentro dos verbos aspectuais que indicam repetição de evento com ideia de frequência (Neves 2000: 64). Note-se, porém, que o pretérito perfeito composto pode ter um valor estativo ou iterativo dependendo do tipo aspetual básico do predicado (v. Oliveira 2013). 
da edição princeps lê-se: podia render a quem não tinha rendido com o offerecimento de todo o mundo (Vieira 1682:74).

A percentagem dos casos com concordância (16) relativamente a todos os casos possíveis de concordância, isto é, com objeto direto feminino ou plural (105) é já pequena: $15,23 \%$. O uso normal em Vieira é, portanto, não fazer concordância: já tenho acabado a carreira (Sermão da Quarta-Feira de Cinza de 1673: \$IV); Temos apontado os meios (Sermão da Terceira Quarta-Feira de Quaresma de 1670: \$VII); vendo a variedade dos desenhos que tinha começado (Sermão de Santo Inácio: \$III); por quem tinha deixado os anjos (Sermão do Mandato: $\$$ III); etc.

Como na História do Futuro, é frequente o uso de TER como auxiliar de verbo [-transitivo]: 88 ocorrências. Alguns exemplos: Com isto tenho acabado (Sermão da Sexagéssima: $\$ \mathrm{X}$ ); As diligências da mãe já tinham chegado (Sermão do Nascimento da Virgem Maria: \$VI); a substância da água se tinha convertido em substância de vinho (Sermão da Quarta-Feira de Cinza de 1672: \$IV); já o demônio tinha entrado em Judas (Sermão da Primeira Dominga de Quaresma: \$V); etc.

Nas Cartas há dois casos de TER + PP que não exprimen a noção de pretérito. Um mais duvidoso em que o suposto pretérito perfeito composto mais parece que descreva uma situação de presente: a tudo me vou sujeitando e tenho sujeito (157). É mais claro o segundo: quis elle [Deus] ter um Filho morto (142). Sem contar estes dois casos, há 341 ocorrências de TER como auxiliar de tempos compostos: parece mais conveniente e praticavel (como já se tem começado a executar) (22); o que já tem abalado a muitos das suas terras (66); As missóes, senhor, continuam, como tenho avisado, com mui conhecido proveito (67-68); pôrem tantos mezes em uma cama, e me terem nella morto tantas vezes (148); Não me diz vossa excellencia quanto tenha ajudado o verão os medicamentos (236); etc. Só 6 casos apresentam concordância com o objeto direto: dezoito ou vinte canoas que havia de ter prevenidas (32); de quem se fiava em ordem secreta que tinha encontrada (36); das felicidades que Deus tem apparelhadas a Portugal (154); etc.

Apenas 6 ocorrências de concordância entre 118 casos de objeto direto feminino ou plural é uma percentagem mínima para este uso na Cartas: 5.08\%. Como se pode ver no Quadro 1, parece que existe um propósito estilístico de abandonar a concordância no género epistolar, talvez pelas caraterísticas específicas deste meio de expressão que, ao que se sabe, não se destinava à publicação no caso de Vieira e, por conseguinte, mantinha a sua essência de conversa relativamente privada (a verdade é que as notícias que chegavam por carta eram frequentemente partilhadas, sendo testemunha disto o próprio Vieira). 


\begin{tabular}{rccc}
\hline & $\begin{array}{c}\text { ocorrências de } \\
\text { concordância }\end{array}$ & $\begin{array}{c}\text { casos possíveis de } \\
\text { concordância }\end{array}$ & percentagem \\
\hline História do Futuro & 5 & 35 & 14.28 \\
Sermöes & 16 & 105 & 15.23 \\
Cartas & 6 & 118 & 5.08 \\
\cline { 2 - 4 }
\end{tabular}

Quadro 1. Concordância com objeto direto em Vieira

Por outro lado, também nas Cartas há um uso frequente de TER como auxiliar com verbo [-transitivo] (86 ocorrências): $A$ armada tem arribado duas vezes (8); não sei o que poderá ter succedido (74); tendo-se retirado com suas armas aos logares mais occultos (79); se tinham já acabado para sempre os captiveiros injustos (83); com esta resolução se tinham despedido (85); se tem recolhido o exercito do Minho (100); quanto se tem contentado delle Pedro Fernandes Monteiro (140); que as queixas de vossa excellencia tenham cessado (249); etc.

\section{A formação dos tempos compostos na obra do Pe. António Vieira com HaVer}

Os tempos compostos com HAVER estáo perfeitamente gramaticalizados na obra de Vieira, de tal modo que não existem casos de interpretação duvidosa, porque HAVER + $\mathrm{PP}$, como tempo composto, já não faz parte de uma estrutura de posse e não é possível a concordância com o objeto direto. Porém, o uso é muito irregular.

A formação dos tempos compostos com HAVER é residual na História do Futuro e nos Sermóes. Só 4 ocorrências aparecem na História do Futuro: o mesmo Cyro reconhece havello recebido de sua mão (128); pelo havermos recebido de pessoa douta (296); etc. Os Sermóes apresentam 15 ocorrências: havendo Cristo deixado por amor dos homens tudo o que tinha no céu (Sermão do Mandato: \$III); Estou vendo, senhores, que já me haveis desempenhado do que ao princípio prometi (Sermão da Quarta-Feira da Quaresma de 1669: \$VI); Havendo el-rei Josias feito grandes serviços a Deus (Sermão da Quarta-Feira de Cinza de 1673: \$IV); Leu-o depois de o haver escrito (Sermão de Nossa Senhora de Penha de França: \$II); etc.

Pelo contrário, nas Cartas há 89 ocorrências de HAVER + PP, não sendo o texto mais extenso dos que foram analisados. Há, sem dúvida, um propósito de estilo no uso de HAVER para a formação dos tempos compostos que já se verificava em autores anteriores como D. Francisco Manuel de Melo (ver Carrasco 2015). Por exemplo: Sinto que os achaques de vossa senhoria se hajam dilatado tanto tempo (154); Muito estimo que vossa senhoria haja passado com bem o trabalho da semana santa (161); haver botado de parte o negocio dos bispados (195); havendo mandado visitar ao gráo duque 
por seu filho (213); são damnos a quem os não ha costumado (248); contrapostos, do que havemos feito (230); está mui contente com lhe haverem chegado de Portugal as suas pensóes (233); o aviso de haver o turco metido soccorro em Kaminies é falso (264); etc.

O índice de uso de HAVER + PP relativamente a TER + PP nas três obras de Vieira apresenta uma grande variância, como se pode verificar no Quadro 2. É claro que passar de $2.96 \%$ ou $4.29 \%$ a $20.70 \%$ é um salto que só se justifica por um propósito de estilo. É de supor que o Pe. António Vieira cuidava muito mais a língua das suas cartas para mostrar a excelência da sua pluma e a capacidade para servir e aconselhar a mais alta aristocracia do reino, a qual nem sempre tinha tratado previamente.

\begin{tabular}{rcccc}
\hline & & HAVER + PP & TER + PP & TOTAL \\
\hline História do Futuro & oc. & 4 & 131 & 135 \\
& & $2.96 \%$ & $97.04 \%$ & \\
Sermöes & oc. & 15 & 335 & 350 \\
& & $4.29 \%$ & $95.71 \%$ & \\
Cartas & oc. & 89 & 341 & 430 \\
\hline
\end{tabular}

Quadro 2. Uso de TER e HAVER na formação dos tempos compostos em Vieira.

De facto, existe também uma variância extrema no uso de HAVER + PP se considerarmos o destinatário das cartas. Neste estudo foram consideradas 144 cartas da edição citada que tiveram 9 destinatários diferentes, considerando que o destinatário da Carta VI é o mesmo que o das primeiras quatro cartas: "A certo ministro da corte". As Cartas VII e VIII, remetidas "Ao principe", têm o mesmo destinatário da Carta V "Ao principe D. Theodosio". A Carta VIII foi assinada no dia 25 de janeiro de 1653 e $\mathrm{D}$. Teodósio só haveria de morrer a 13 de maio desse mesmo ano.

A maior parte das cartas são relativamente breves, ocupando não mais de 2 páginas, mas as 9 cartas "A el-rei" são muito mais extensas - só a Carta XVII ocupa 17 páginas. Os destinatários com mais cartas são D. Rodrigo de Meneses (62 cartas) e o Marquês de Gouvêa (61 cartas), mas todas elas são breves. Por isso, para fazer o cálculo, decidi considerar o número aproximado de páginas (sem ter em conta fracçóes de páginas) que ocupam as missivas de cada destinatário. No Quadro 3 podemos verificar a média de casos de HAVER + PP por página em cada destinatário. 


\begin{tabular}{rcccc}
\hline & cartas & páginas & ocorrências & média \\
\hline Ao principe D. Theodosio & 3 & 6 & 0 & 0 \\
A rainha & 1 & 2 & 0 & 0 \\
A el-rei & 9 & 53 & 5 & 0.09 \\
A certo ministro da corte & 5 & 12 & 4 & 0.33 \\
A D. Rodrigo de Menezes & 62 & 89 & 30 & 0.33 \\
Ao marquez de Gouvêa & 61 & 79 & 43 & 0.54 \\
Ao duque de Cadaval & 1 & 3 & 4 & 1.33 \\
Ao muito reverendo padre provincial do Brazil & 1 & 2 & 3 & 1.5 \\
\hline
\end{tabular}

Quadro 3. HAVER + Pp nas Cartas do Pe. António Vieira

As cartas que dirige à família real têm uma presença mínima de HAVER + PP por página: de 0 a 0.09 . Não devemos esquecer que o $P^{e}$. António Vieira passou ao serviço do rei desde o início da Restauração e foi muito favorecido por D. João IV. Apesar de as formas de tratamento serem muito cuidadas e manter sempre o máximo respeito, o autor náo precisa de usar uma linguagem especialmente alambicada e retórica. Porém, entre a aristocracia cortesã que governava o reino (e com quem teve alguns problemas depois da morte de D. Joáo IV), aumenta o uso de HAVER + PP segundo a categoria do destinatário: de 0.33 nas cartas de "certo ministro da corte" e "D. Rodrigo de Menezes" (que então estava ao serviço de D. João da Silva, II marquês de Gouveia, como se deduz das cartas onde se fala do "marquez") até 0.54 das cartas do próprio marquês e daí a 1.33 do duque de Cadaval. Chama a atenção a média de 1.5 ocorrências por página da carta "Ao muito reverendo padre provincial do Brazil", talvez porque náo tivesse confiança com o superior dos jesuítas brasileiros ou talvez porque as cartas dos jesuítas eram normalmente copiadas, remetidas para vários sítios e divulgadas internamente, de modo que o autor cuidava especialmente a retórica do seu estilo nestes casos.

A análise de textos desde início do século XVI até meados do século XVII mostrava como HAVER + PP primeiro deixou de ser usado na língua cortesã (embora pudesse conservar-se noutros usos) e mais tarde foi recuperado no estilo culto e literário com caraterísticas mais próximas do seu uso em castelhano do que o tradicional uso dos tempos compostos em português, sem dúvida por influência das letras do país vizinho, e com um propósito estilístico ou retórico. Esta situação haveria de culminar na obra de D. Francisco Manuel de Melo, pois nalgumas das suas obras HAVER + PP é mais frequente do que TER + PP. Vieira porém é muito mais renuente ou comedido do que Melo, se bem que também ele escolha propositadamente aquele auxiliar para produzir determinados efeitos de maior requinte no leitor. 


\section{A formação dos tempos compostos na obra do Pe. António Vieira com SER}

O uso do verbo SER para a formação dos tempos compostos, sempre com verbo [-transitivo], era ainda habitual na primeira metade do século XVI, de tal modo que, por exemplo, nas Cartas de D. Joáo III só se usa SER com estes verbos, todos de movimento $^{17}$ (Mattos e Silva 2002a) e na obra de João de Barros também se usa SER com estes verbos, mas já o auxiliar Ter é usado igualmente (Mattos e Silva 2002b). Por sua vez, Bernardim Ribeiro usa sistematicamente SER + PP com verbos de movimento (mudar, ir, passar), com acabar, com verbos que significam 'morrer' e com o verbo nascer (Carrasco 2012 e 2013) e só num caso, na Écloga IV, encontramos o uso de TER com o verbo passar. Já em meados do século XVII, a obra de D. Francisco Manuel de Melo conserva o uso de SER + PP com verbo [-transitivo], mais concretamente com verbos de movimento (chegar, vir, ir, entrar, arribar e sair), verbos que significam 'morrer' (morrer, falecer) e o verbo incoativo amanhecer. Porém, o escritor barroco usa já com estes mesmos verbos indistintamente os auxiliares TER e HAVER (ver Carrasco 2015).

A obra de Vieira ainda conserva o uso de SER + PP com alguns verbos de movimento (entrar, chegar, partir, etc.), bem como com morrer, nascer, acabar e passar (usado para 'passar tempo' e também com o significado de 'acontecer'). As ocorrências são, contudo, muito escassas nas três obras consideradas: 4 na História do Futuro, 27 nos Sermóes e 14 nas Cartas. Pelo contrário, Vieira usa os auxiliares Ter e HAVER com

17. Utilizo a expressão tradicional "verbos de movimento" por coerência com os trabalhos anteriores sobre a formação dos tempos compostos no período clássico, dos quais este é continuação, apesar de atualmente ser considerada pouco rigorosa. Isto não é um problema porque são poucos os verbos que formam os tempos compostos com SER e todos são aqui referidos. De facto, não havendo já na língua clássica um uso sistemático de SER + PP com verbo [-transitivo], parece que os verbos que ainda usam este auxiliar neste período se reduziram a determinados campos semânticos. Por outro lado, é verdade que estes "verbos de movimento" são os que aparecem mais frequentemente nos tempos compostos com SER. Segundo Maria Helena de Moura Neves, os "verbos de movimento" não existem como categoria, de modo que semanticamente aparecem no grupo muito mais amplo dos predicados dinâmicos de açôes ou atividades (ver Neves 2000: 25-26). Porém, como campo semântico, os supostos "verbos de movimento" que neste período da língua portuguesa usam (ou podem usar) o verbo SER como auxiliar para a formação dos tempos compostos podem ser incluídos no grupo dos que exprimem o início, o transcurso ou a interrupçáo do deslocamento do sujeito. Deste modo, todos os verbos de movimento conjugados com SER que aparecem nos textos analisados podem ser classificados numa das duas classes de verbos de movimento propostas por Levin (1993): nos inherently directed motion verbs (verbos de movimento com uma direção inerente), e não nos manner of motion verbs (verbos que exprimem o modo de se mover como voar, nadar, correr, saltar, passear, dançar, etc.) Em todo o caso, a construçáo de SER + PP, unida já neste período a muito poucos verbos, acaba por funcionar quase como expressôes linguísticas, até chegar ao ponto de constituírem, no caso de Francisco Xavier de Oliveira, verdadeiras construçóes fossilizadas. 
verbo [-transitivo] sistematicamente, mesmo com esses mesmos verbos em que ainda se conserva SER + PP, como se pode verificar no Quadro 4.

\begin{tabular}{rccc}
\hline & SER + PP & TER + PP & HAVER + PP \\
\hline $\begin{array}{r}\text { verbos de movimento (chegar, entrar, } \\
\text { partir, cair, passar, sair, vir, arribar, embar- }\end{array}$ & 23 & 56 & 18 \\
car, ir, recolher-se, retirar-se, descer, meter, & & & \\
mudar-se, parar) & & 0 & 1 \\
verbos que significam 'morrer' (morrer, & 11 & 4 & 4 \\
falecer) & & & \\
outros casos de passar ('passar tempo', & 4 & 2 & 1 \\
acontecer') & & 6 & 0 \\
nascer & 6 & 140 & 26 \\
acabar & 1 & 208 & 50 \\
outros casos de verbo [-transitivo] & 0 & $68.65 \%$ & $16.50 \%$ \\
TOTAL DE OCORRÊNCIAS & 45 & & \\
frequência & $14.85 \%$ & & \\
\hline
\end{tabular}

Quadro 4. Tempos compostos con verbo [-transitivo] em Vieira.

A obra de Vieira mostra como ser é ainda usado na formação dos tempos compostos no fim do século XVII, especialmente com nascer, morrer (e sinónimos) e com determinados verbos de movimento. Porém, HAVER (com menos ocorrências, por ser usado pouco por Vieira) e TER são muito mais usados com verbo [-transitivo] $(85,15 \%)$ do que SER, mesmo com verbos de movimento. De facto, percebe-se em Vieira um uso de SER combinado só com alguns verbos como chegar, nascer ou morrer. Relativamente ao uso de SER + PP em D. Francisco Manuel de Melo, constata-se em Vieira uma diminuição importante deste verbo, que ainda era maioritário com determinados verbos na obra do poeta barroco e que, no conjunto de todos os verbos usados por Melo com SER, 52.3\% das ocorrências são com este verbo como auxiliar (ver Carrasco 2015: 90-91) ${ }^{18}$.

\section{Os tempos compostos no século XVIII}

Comparativamente com HAVER + PP, surpreende a lentidáo no processo de gramaticalização de TER + PP e de substituição de SER + PP com determinados verbos. Até fim do século XVII, como vimos no caso de Vieira, todos os usos tradicionais dos auxiliares

18. Estes são os verbos usados por Melo com SER e a sua frequência (relativamente a ser usados COM TER Ou HAVER): chegar (54.5), vir (83.3), ir (33.3), entrar (50), arribar (33.3), sair (16.7), morrer (62.5), falecer (100) e amanhecer (50). 
TER e SER continuam vivos, se bem que se perceba uma diminuição evidente relativamente à primeira metade do século. Em relação à situação que existe na língua portuguesa dos nossos dias, e à evolução muito mais rápida que se verificou em castelhano (v. Carrasco 2015: 80-82), pode-se afirmar que, pelo menos na linguagem literária, ainda se mantinham no século XVIII as caraterísticas conservadoras dos séculos XVI e XVII.

Em Vida e ações do famoso e felicíssimo Sevagy, do primeiro terço do século xviII, ainda se encontram ocorrências de concordância com objeto direto: subindo a tomar posse da Fortaleza, jà estava nella, e jà a tinha bem presidiada (27); para que antes de amanhecer tivessem tomadas as entradas, e sahidas da Cidade (37); tinha tomados todos os caminhos ao longe com muito fieis espias (39); etc. A frequência é notável: $28.57 \%$ (6 casos de 21 possíveis concordâncias). Pelo contrário, nenhuma das quatro obras de fins do século XVIII analisadas apresentam casos de concordância com objeto direto, o que parece indiciar uma paulatina desaparição deste uso ao longo de Setecentos. Não foi considerado um caso de $O$ criado de si mesmo: Elle D. Ana me ordena / q vos tenha recolhida / no meu quarto (39r). Note-se que neste caso não existe expressão da noção de pasado e, por conseguinte, não se pode considerar tempo composto.

Também SER + PP apresenta alguma evolução neste século, mas sem ter desaparecido completamente. É Vida e açôes do famoso e felicíssimo Sevagy que apresenta mais casos e com mais verbos: 9 ocorrências com morrer, chegar, fugir, passar (tempo) e acabar. Exemplos: mandando dizer ao Sevagy, que naó era chegado para receber os seus presentes (83); assim que soube era chegado, desappareceo todo o mal (123); achou que Sevagy era fugido (137); etc. Estes verbos só formam os tempos compostos com SER, mas no texto aparecem também entrar e partir conjugados com TER: lhe tinha entrado desejo de a ver (95); fez correr fama, que se tinha partido para o Reyno de Carnate (155) ${ }^{19}$.

Nenhuma das duas comédias analisadas possui ocorrências de SER + PP, mas os dois elogios de Francisco Xavier de Oliveira, ainda em 1798, oferecem-nos alguns casos. São poucos: 3 no Elogio do Condestável e 6 no Elogio de Afonso de Albuquerque. Exemplos: Porém ainda naó era chegada a época das suas victorias (13); ainda naó era chegada a época desta pública, e geral felicidade (53); Era passado hum lustro (152); etc. Note-se que SER aparece como auxiliar apenas de chegar (8 ocorrências) e passar (1 ocorrência), sendo que chegar também aparece conjugado com TER em 1 ocasiáo. Esta redução do uso de SER + PP indicia uma possível fossilização reservada a tratados

19. Existe também um caso de marchar com TeR: Sextaghan naô tinha marchado huma legoa, quando vio dez mil Cavallos de Sevagy (54). O verbo marchar aparece neste exemplo usado como [+ transitivo], de modo que náo pode formar tempos compostos com ser. Por outro lado, o facto de ser um francesismo introduzido na época clássica (no Dicionário Houaiss da língua portuguesa é documentado em 1613 - ver Houaiss / Villar \& Franco 2004: s.v.) não alteraria a análise do uso de SER + PP, porque mesmo aparecendo como verbo [-transitivo], o facto de não formar os tempos compostos com SER por ser um estrangeirismo confirmaria que SER deixou de ser produtivo na formação dos tempos compostos. 
de um professor de retórica e poética, como era o autor, mas já inexistente na língua falada da época, como se pode deduzir da sua ausência completa nas duas comédias.

Parece confirmar que não era um uso vivo para a formação dos tempos compostos o facto de Oliveira nos oferecer casos em que SER é substituído por ESTAR: Albuquerque [...] estás chegado ao termo da tua guerreira expediçaó (164); e está chegado o tempo d'a pôr em execuçaô (207); etc. O facto de Oliveira usar SER e ESTAR com particípio de chegar mostra que, provavelmente, o autor relacionava estes casos mais com o valor predicativo dos dois verbos do que com a expressáo temporal de pretérito e, por conseguinte, contamina o tempo composto com as variantes aspectuais da oposição SER/ESTAR (ver Mateus / Brito / Duarte \& Faria 1983: 136-142).

Por fim, o uso de HAVER + PP mantém as caraterísticas que já tinha na sua recuperação no fim do século XVI e início do XVII e que fundamentalmente ainda tem na atualidade: máxima gramaticalização e uso exclusivo em registo escrito e culto. A variância no uso de HAVER confirma que náo responde a um uso vivo na língua, porque se assim fosse devia aparecer com uma frequência semelhante em todas as obras. Pelo contrário, só Francisco Xavier de Oliveira, o autor que revela o propósito estilístico mais culto, regista percentagens elevadas $(35.71 \%$ e $50 \%)$, ao passo que as duas comédias quase não têm ocorrências (Quadro 5).

\begin{tabular}{rcc}
\hline & $\begin{array}{c}\text { TER + PP } \\
\text { oc. (frequência) }\end{array}$ & $\begin{array}{c}\text { HAVER + PP } \\
\text { oc. (frequência) }\end{array}$ \\
\hline Vida e açôes do famoso e felicíssimo Sevagy & $48(90.57)$ & $5(9.43)$ \\
Elogio do Condestável D. Nuno Álvares Pereira & $36(64.29)$ & $20(35.71)$ \\
Elogio de Afonso de Albuquerque & $13(50)$ & $13(50)$ \\
O criado de si mesmo & $27(96.43)$ & $1(3.57)$ \\
Os peraltas mascarados em Almada & $25(100)$ & $0(0)$ \\
\hline
\end{tabular}

Quadro 5. Uso de TER e HAVER nas obras do século XVIII

O único caso de HAVER + PP em $O$ criado de si mesmo, para além de ser pouco significativo, pode ter explicação no facto de ser a versão de uma obra espanhola do século XVII. Eis o passo onde aparece: e apenas haver chegado / de Espanha, aonde servi I de Militar quatro annos (9r). Quem fala é D. João de Alvarado, um cavaleiro que, por contraste com o seu criado, tem uma linguagem marcadamente cuidada, o que também explicaria a escolha para ele do verbo HAVER como auxiliar. 


\section{Outros indícios de gramaticalização}

Há dois fenómenos relacionados com a gramaticalização na formação dos tempos compostos que já foram analisados nos séculos XVI e XVII: a anteposição do particípio ao verbo auxiliar e a interpolação de elementos entre o auxiliar e o particípio. A anteposição quase desaparece na passagem do século XVI para o XVII, mas ainda é possível encontrar alguns raros exemplos na obra em prosa de D. Francisco Manuel de Melo: admirado me tem essa vossa relação (v. Carrasco 2015: 92). Porém, nem na obra de Vieira nem nos textos analisados do século XVIII foi encontrada alguma ocorrência da anteposição.

Quanto à interpolação, D. Francisco Manuel de Melo apresenta uma frequência de $18.1 \%$ com HAVER, $12.8 \%$ com ter e 38.2\% com SER (v. Carrasco 2015: 92), não sendo inferior a autores de fins do século xvi ou início do xvir como Duarte Nunes de Leão, Sebastião Toscano e Rodrigues Lobo (v. Carrasco 2014: 95-97). A interpolaçáo ainda aparece na obra do Pe. António Vieira, mas os elementos interpolados, ao contrário do que é possível encontrar em D. Francisco Manuel de Melo, são sempre poucos, normalmente algum advérbio ou o sujeito: havendo-se logo cortado a cabeça a um que quiz resistir (Vieira 1854: 243); tinha já acabado a carreira (Vieira 2008: Sermão da Quarta-Feira de Cinza em Roma 1673, \$IV); tinha Christo promettido a seu primeyro Rey (Vieira 1718: 81); etc. O período mais comprido entre auxiliar e particípio que se encontra em Vieira é este: haverem alguns de seus maiores concorrido (Vieira 1854: 218). O uso da intercalação é, portanto, comedido e também muito mais escasso do que na obra de D. Francisco Manuel de Melo, como se pode ver no Quadro 6.

\begin{tabular}{rlll}
\hline & \multicolumn{1}{c}{ TER } & \multicolumn{1}{c}{ HAVER } & \multicolumn{1}{c}{ SER } \\
\hline História do Futuro & $6[131](4.58 \%)$ & $0[4](0 \%)$ & $1[4](25 \%)$ \\
Cartas & $30[341](8.8 \%)$ & $11[89](12.36 \%)$ & $0[14](0 \%)$ \\
Sermóes & $25[335](7.46 \%)$ & $3[15](20 \%)$ & $7[27](25.92 \%)$ \\
TOTAL: & $61[807](7.56 \%)$ & $14[104](13.46 \%)$ & $8[45](17.78 \%)$ \\
\hline
\end{tabular}

Quadro 6. Interpolação na obra de Vieira: ocorrências [total de tempos compostos] (frequência).

A frequência de uso é inferior à de Melo, e ainda mais se considerarmos apenas os tempos compostos mais usados (com ter e, no caso das Cartas, HAVER). As ocorrências nos outros casos são escassas e, por isso mesmo, poucos casos de interpolação podem dar resultados muito diferentes, de extrema variância: de $0 \%$ até $25.92 \%$.

Quanto às obras do século XVIII, como se pode ver no Quadro 7, observa-se em primeiro lugar uma presença notável de interpolação em Sevagy, superior até à que aparecia em Vieira, o que demonstra que na primeira metade deste século o fenóme- 
no perdurava sem que seja possível verificar nenhuma mudança em relação ao século anterior, inclusivamente com a interpolação de muitos elementos. Alguns exemplos: Tinha Neotagy fóra dos oito mil Cavallos, posto dous mil nos dous lados, que naquella paragem havia ter o Exercito (55); mil e quinhentos Mogoles, dos que Rayá havia para este effeito deixado (99); conheceo logo era tudo para elle acabado (158); etc.

\begin{tabular}{rlll}
\hline & \multicolumn{1}{c}{ TER } & \multicolumn{1}{c}{ HAVER } & \multicolumn{1}{c}{ SER } \\
\hline Vida e açóes do famoso, e felicíssimo Sevagy & $9[48](18.75 \%)$ & $1[5](20 \%)$ & $4[9](44.44 \%)$ \\
Elogio do Condestável D. Nuno Álvares Pereira & 7 [36] (19.44\%) & $2[20](10 \%)$ & $0[3](0 \%)$ \\
Elogio de Afonso de Albuquerque & $3[13](23.07 \%)$ & $1[13](7.69 \%)$ & $0[6](0 \%)$ \\
O criado de si mesmo & $2[27](7.41 \%)$ & $0[1](0 \%)$ & $0[0](--)$ \\
Os peraltas mascarados em Almada & $2[25](8 \%)$ & $0[0](-)$ & $0[0](-)$ \\
\hline
\end{tabular}

Quadro 7. Interpolação no século xviII: ocorrências [total de tempos compostos] (frequência)

No fim do século XVIII ainda encontramos alguma presença de interpolaçáo, mais reduzida, nas duas comédias: $7.41 \%$ e $8 \%$ só com o verbo TER. Ocorrências em O criado de si mesmo: $q$ me tinha o cazamento ajustado (9r); Atenciozo, e prudente / vos tenho D. Lope ouvido (20v-21r). Ocorrências em Os peraltas mascarados: tenho-a de algum modo civilizado (1); tenha-o assim entendido (26). Porém, nos dois exercícios retóricos de Francisco Xavier de Oliveira voltamos a encontrar uma liguagem conservadora, pois a interpolação apresenta uma frequência superior a Sevagy e às obras de Vieira com o verbo TER: $19.44 \%$ e $23.07 \%$. Exemplos: Até aqui temos sómente visto o genio de Nuno (14); a par dos maiores guerreiros, que tem do seu nome enchido a terra (70); cujo dominio haviaó já perdido pelas leis da guerra (120); haviaó unicamente concurrido para a feliz execuçaó de todas as suas bellicas empresas (172); Já do rico trafico da pimenta se tem Albuquerque apoderado (198); etc.

Apesar de perseverar este fenómeno nos últimos anos de Setecentos, pode-se deduzir que a interpolaçáo (nomeadamente com muitos elementos interpolados) era infrequente na língua coloquial, como revelam as duas comédias, mas o modelo de língua literária ou culta ainda a utilizava de modo abundante. É previsível que as grandes mudanças que iria viver a sociedade portuguesa poucos anos depois e a aparição de um novo modelo cultural, relacionado com o romantismo, eliminariam rapidamente estes traços mais conservadores da formação dos tempos compostos em português até definir as caraterísticas que possuem nos nossos dias. 


\section{Conclusôes}

O corpus utilizado por Harre (1991) não foi suficiente para encontrar todas as realizaçóes possíveis de tempo composto nos séculos XVII e XVIII, nem para seguir com mais detalhe a sua evolução. Deste modo, pudemos comprovar que os casos de TER + PP com verbo [-transitivo] não só se registam em Vieira, mas são mais numerosos do que SER + PP. De facto, a frequência de uso de HAVER com estes verbos é também maior do que com SER. Aliás, ao contrário do que supunha Harre, SER + PP não desaparece no século XVIII, embora o seu uso fique reduzido a alguns verbos de movimento e outros raros casos de verbo [-transitivo] como acabar. No fim do século XVIII, SER + PP tinha um uso próximo das expressóes fossilizadas.

A concordância de particípio e objeto direto com TER não é sistemática em Vieira, como afirmava Harre, mas bastante minoritária: 5.08\%, 14.28\% e 15.23\% de entre os casos de possível concordância nas três obras analisadas. Quanto ao século XVIII, comparativamente com a obra de Vieira, verifica-se nas primeiras décadas uma frequência igual ou superior, mas já nos anos finais do século a concordância tinha desaparecido completamente.

No século XVI o uso de HAVER + PP quase desaparece e só começa a ser recuperado nas modalidades mais cultas da língua. Ao contrário do que propóe Harre, este uso (que depende do gosto e do estilo de cada autor) continua igual nos séculos XVII e XVIII, coincidindo em grande medida com o uso dos nossos dias. Por outro lado, HAVER + PP não apresenta nunca casos de concordância com objeto direto desde a recuperação do seu uso no fim do século XVI, e é isso mesmo que se verifica nas obras analisadas dos séculos XVII e XVIII.

A evolução dos tempos compostos ao longo dos séculos XVII e XVIII foi lenta, perseverando em usos que desaparecem posteriormente, como o auxiliar SER, a concordância com objeto direto ou a interpolação de elementos entre auxiliar e particípio. Mas também foi possível constatar uma progressiva gramaticalização e uma aproximação a caraterísticas mais modernas: a anteposição desaparece em Vieira e não foi registada nas obras do século XVIII; o uso de SER + PP é cada vez mais raro e acaba por perder em grande medida a expressão de tempo composto; a interpolação é já pouco frequente nas obras do século XVII analisadas. Por fim, a despeito dos pressupostos da retórica neoclássica, as duas comédias analisadas (muito mais fieis à língua coloquial) oferecem uma situação que se aproxima muito dos tempos compostos no português atual: opção quase exclusivamente de TER como auxiliar, escassa presença da interpolação e abandono da anteposiçáo e da concordância com objeto direto. 


\section{Referências bibliográficas}

Anónimo. 1788. Comedia Intitulada O Creado de si mesmo. (Manuscrito da Biblioteca Nacional de Portugal). http://purl.pt/24160 (08/02/2019).

Anónimo. 1790. Os peraltas mascarados em Almada. Lisboa: Off. Antonio Gomes. http://purl.pt/14901 (08/02/2019).

Becker, Martin. 2016. O pretérito perfeito composto em diacronia - uma evolução perfeita? Estudos de lingüistica galega 8, 25-43. http://dx.doi.org/10.15304/elg.8.3057 (22/09/2019).

Brocardo, Maria Teresa. 2014. Tópicos de história da língua portuguesa. Lisboa: Edições Colibri.

Cardeira, Esperança. 2012. Elementos para a periodização do português. Em Roberval Teixeira e Silva / Qiarong Yan / Maria Antónia Espadinha \& Ana Varani Leal (eds.), III SIMELP: A formação de novas geraçóes de falantes de português no mundo. Macau: Universidade de Macau. http:// simelp.fflch.usp.br/sites/simelp.fflch.usp.br/files/inline-files/III-SIMELP-final-179-212.pdf $(21 / 04 / 2019)$.

Cardeira, Esperança. 2013. Do português médio ao clássico: o Cancioneiro Geral de Garcia de Resende. Em Emili Casanova Herrero \& Cesareo Calvo Rigual (eds.), Actas del XXVI Congreso internacional de lingüistica y de filología románicas (Valencia, 2010), vol. I. 543-554. Berlin / Boston: De Gruyter Mouton. https://doi.org/10.1515/9783110299892.543

Carrasco González, Juan M. 2012. Uso de haver en la Menina e Moça: Bernardim Ribeiro en la frontera del portugués arcaico. Em Ana María Cestero Mancera / Isabel Molina Martos \& Florentino Paredes García (eds.). La lengua, lugar de encuentro: actas del XVI Congreso Internacional de la Alfal. 2515-2524. Alcalá de Henares: Servicio de Publicaciones de la Universidad de Alcalá. https:// www.mundoalfal.org/alfal2011/index.html\#/pdf/284alfal.pdf (21/04/2019).

Carrasco González, Juan M. 2013. Algunos indicadores del portugués clásico en la obra de Bernardim Ribeiro. Estudis Romànics 35, 173-188. http://revistes.iec.cat/index.php/ER/article/ view/72719/72484

Carrasco González, Juan M. 2014. Evolución de los tiempos compuestos en portugués durante los siglos XVI y XVII. Archivum 64, 77-100. https://doi.org/10.17811/arc.64.2014.77-100

Carrasco González, Juan M. 2015. Influencia del español en la prosa barroca portuguesa: los tiempos compuestos. RILCE. Revista de Filología Hispánica 31.1, 79-96. https://revistas.unav.edu/index. $\mathrm{php/rilce/article/view/238/52}$

Carrasco González, Juan M. 2019. Análise de macrocorpora e microcorpora para estudos de linguística histórica. Em Ernestina Carrilho / Ana Maria Martins / Sandra Pereira \& João Paulo Silvestre (orgs.), Estudos linguisticos e filológicos oferecidos a Ivo Castro. 415-429. Lisboa: Centro de Linguística da Universidade de Lisboa. http://hdl.handle.net/10451/39619

Castro, Ivo. 2006. Introdução à história do português. Lisboa: Edições Colibri. (Segunda edição revista e muito ampliada).

Givón, Talmy. 1975. Serial verbs and syntactic change: Niger-Congo. Em Charles N. Li (org.), Word order and word change. 47-112. Austin: University of Texas Press.

Gonçalves, Sebastião Carlos Leite / Maria Célia Lima-Hernandes / Vânia Cristina Casseb-Galvão \& Cristina dos Santos Carvalho. 2007. Tratado geral sobre gramaticalização. Em Sebastião Carlos Leite Gonçalves / Maria Célia Lima-Hernandes \& Vânia Cristina Casseb-Galvão (org.), Introdução à gramaticalização. Princípios teóricos \& aplicação. 15-66. São Paulo: Parábola Editorial. 
Gross, Maurice. 1981. Les bases empiriques de la notion de prédicat sémantique. Languages 63, 7-52. https://doi.org/10.3406/lgge.1981.1875

Harre, Catherine E. 1991. Tener + Past Participle. A case study in linguistic description. London / New York: Routledge.

Hopper, Paul J. 1991. On some principles of grammaticalization. Em Elizabeth C. Traugott / Bernd Heine (orgs.), Approaches to grammaticalization. 59-90. Amsterdam: John Benjamins.

Houaiss, Antônio / Mauro de Salles Villar \& Francisco Manoel de Mello Franco (dir.). 2004. Dicionário Houaiss da língua portuguesa. Rio de Janeiro: Objetiva. (1. a reimpressão com alteraçôes).

Lehmann, Christian. 1985. Grammaticalization: Synchronic variation and diachronic change. Lingua and stile 20.3, 303-318.

Levin, Beth. 1993. English verb classes and alternations: A preliminary investigation. Chicago / London: The University of Chicago Press.

Mateus, Maria Helena Mira / Ana Maria Brito / Inês Silva Duarte \& Isabel Hub Faria. 1983. Gramática da língua portuguesa. Elementos para a descrição da estrutura, funcionamento e uso do português actual. Coimbra: Livraria Almedina.

Mattos e Silva, Rosa Virgínia. 1981. Um aspecto do auxiliar no português arcaico. Tulane studies in romance linguistics and literature 10, 93-109.

Mattos e Silva, Rosa Virgínia. 1989. Estruturas trecentistas: elementos para uma gramática do português arcaico. Lisboa: Imprensa Nacional - Casa da Moeda.

Mattos e Silva, Rosa Virgínia. 1993. O português arcaico: morfologia e sintaxe. São Paulo: Contexto.

Mattos e Silva, Rosa Virgínia. 1995. Variação e mudança no português arcaico: ter ou haver em estruturas de posse. Em Cilene da Cunha Pereira \& Paulo Roberto Dias Pereira (coords.), Miscelânea de estudos lingüisticos, filológicos e literários in memoriam Celso Cunha. 299-311. São Paulo: Nova Fronteira.

Mattos e Silva, Rosa Virgínia. 2002a. Vitórias de ter sobre haver nos meados do século xvı: usos e teorias em João de Barros. Em Rosa Virgínia Mattos e Silva \& Américo Venâncio Lopes Machado Filho (eds.), O português quinhentista: estudos linguisticos. 119-142. Salvador: Universidade Federal da Bahia / Universidade Estadual de Feira de Santana.

Mattos e Silva, Rosa Virgínia. 2002b. A variação ser/estar e haver/ter nas Cartas de D. João III entre 1540 e 1553: comparação com os usos coetâneos de João de Barros. Em Rosa Virgínia Mattos e Silva \& Américo Venâncio Lopes Machado Filho (eds.), O português quinhentista: estudos linguisticos. 143-160. Salvador: Universidade Federal da Bahia / Universidade Estadual de Feira de Santana.

Mattos e Silva, Rosa Virgínia. 2006. O português arcaico: fonologia, morfologia e sintaxe. São Paulo: Contexto.

Neves, Maria Helena de Moura. 2000. Gramática de Usos do Português. São Paulo: Editora UNESP.

Oliveira, Fátima. 2013. Tempo verbal. Em Eduardo Paiva Raposo / Vicente Graça \& Rita Veloso, Gramática do Português, vol. I, 509-553. Lisboa: Fundação Calouste Gulbenkian.

Oliveira, Francisco Xavier de. 1798. Elogio do Condestable D. Nuno Alvares Pereira / Francisco Xavier de Oliveira. Lisboa: Offi. De João Antonio da Silva. http://purl.pt/14410 (08/02/2019). 
Osório, Paulo. 2008. Linguística histórica e história da língua: aportaçóes teóricas e metodológicas. Em I Simpósio mundial de estudos da língua portuguesa, São Paulo, 1 a 5 de setembro de 2008. São Paulo: Universidade de São Paulo. http://simelp.fflch.usp.br/sites/simelp.fflch.usp.br/files/ inline-files/S401.pdf (20/04/2019).

Pacheco, Caetano de Gouvêa. 1730. Vida e acçoens do famoso e delicissimo Sevagym, da India Oriental / escrita por Cosme da Guarda, natural de Murmugão... Lisboa Occidental: na Officina da Musica: vendese na mesma Offic. http://purl.pt/13851 (07/02/2019).

Pottier, Bernard. 1978. Les voix du français. Semantique et syntaxe. Cahiers de lexicologie, 33.2, 3-39.

Saraiva, António José / Lopes, Óscar. 1982. História da literatura portuguesa. Porto: Porto Editora. (12. a ediçáo, corrigida e actualizada).

Silva, Inocêncio Francisco da. 1987. Diccionario bibliographico portuguez. Estudos de Innocencio Francisco da Silva applicaveis a Portugal e ao Brasil. Tomo Segundo. Lisboa: Na Imprensa Nacional, M DCCC LIX. (Reeditada em reprodução fac-similada no mês de maio de 1987, [Lisboa]: Imprensa Nacional - Casa da Moeda).

Silva, Inocêncio Francisco da. 1996. Diccionario bibliographico portuguez. Estudos de Innocencio Francisco da Silva applicaveis a Portugal e ao Brasil. Tomo Terceiro. Lisboa, Na Imprensa Nacional, M DCCC LIX. (Reprodução fac-similada, [Lisboa]: Imprensa Nacional - Casa da Moeda).

Vieira, António. 1679. Sermoens do P. Antonio Vieira...: primeyra parte... Lisboa: na officina de Joam da Costa. http://purl.pt/297 (26/02/2019).

Vieira, António. 1682. Sermoens do P. Antonio Vieira...: segunda parte... Lisboa: na officina de Miguel Deslandes. E à sua custa, \& de Antonio Leyte Pereyra mercador de. http://purl.pt/292 (26/02/2019).

Vieira, António. 1718. Historia do futuro: Livro anteprymeyro prologomeno a toda a historia do futuro, em que se declara o fim, \& se provaó os fundamentos della. Materia, verdade, \& utilidades da historia do futuro. Na officina de Antonio Pedrozo Galram. (Foi utilizado o exemplar da Bodleian Libraries, University of Oxford, digitalizado pela Google Books Library Project).

Vieira, António. 1854. Cartas do Padre Antonio Vieira. Tomo I. Lisboa: Editores, J. M. C. Seabra \& T. Q. Antunes. (Faz parte da edição das obras completas do autor).

Vieira, António. 2008. Sermóes. RocketEditionTM. (Edição em PDF de eBooksBrasil. Fonte digital: Ministério da Cultura, Fundação Biblioteca Nacional, Departamento Nacional do Livro). http:// www.iphi.org.br/sites/filosofia_brasil/Padre_Ant\%C3\%B4nio_Vieira_-_Serm\%C3\%B5es.pdf (06/02/2019). 